$13^{\text {th }}$ International Conference on

AEROSPACE SCIENCES \& AVIATION TECHNOLOGY,

$\boldsymbol{A S A T}$ - 13, May 26 - 28, 2009, E-Mail: asat@mtc.edu.eg

Military Technical College, Kobry Elkobbah, Cairo, Egypt

Tel : +(202) $24025292-24036138$, Fax: +(202) 22621908

\title{
Aircraft Guidance-System Logic Design for a Fully Autonomous Mission
}

\author{
H. E. Taha*, M. Bayuomi ${ }^{* *}$, G. M. El-Bayoumi ${ }^{* * *}$ and S. D. Hassan ${ }^{\dagger}$
}

\begin{abstract}
In the aircraft guidance-system design-process, a number of autopilots are designed at certain flight conditions. An autopilot is responsible for a certain task not the whole mission, e.g., an autopilot can be responsible for the a/c to have a certain rate of climb, velocity, or altitude...etc. And a need arises for a supervisory control system that manages the engagement and disengagement of each designed autopilot, passing the command inputs to them for the a/c to accomplish the whole mission. It looks like the supervisory control system existing in DCS's (Distributed Control Systems). In this paper, the logic of the online-software for such systems is presented, clarifying the inputs, outputs, and timing of the system. Also the logic of the Ground Control Station (GCS) software is presented. A realistic mission is adopted to clarify the operation of the guidance system.
\end{abstract}

Keywords: Aircraft Guidance, and Autonomous Flight

\section{Introduction}

One of the techniques used in a/c guidance along a prescribed trajectory is to design certain autopilots at some flight conditions. Then the $\mathrm{a} / \mathrm{c}$ is kept stable and under command at these flight conditions, i.e., if the a/c is required to have a certain velocity, altitude, or heading...etc. the responsible autopilot can be engaged to accomplish this task. Then a supervisory control system is to be designed to engage and disengage each autopilot at the appropriate times, feeding them with the appropriate command inputs. This system has two programs; GCS software which deals with the $\mathrm{a} / \mathrm{c}$ operator in a user friendly way, receives the $\mathrm{a} / \mathrm{c}$ mission description, and saves this data in an appropriate manner. And the online software which is the main system component; it receives the saved data from the GCS software, manages the engagement and disengagement of each autopilot, and feeds them with the desired command inputs. These two components are to be discussed in this paper.

\section{Mission Profile}

An air-to-surface mission for a fixed target is planned, [1]. This mission represents a simple striking mission that can be either training or real mission. The mission consists of climb, cruise, descent, releasing bomb, climb, cruise, descent, and steering at each necessary point. The overall mission runs about 30 minutes. The plane view of the mission is illustrated in Fig. 1, while the altitude and speed information at each steering point are provided in Fig.2 and Table 1.

\footnotetext{
Teaching Assistant, Aerospace Eng. Dept., Cairo University / egyhezzat@gmail.com Assistant Professor, Aerospace Eng. Dept., Cairo University / msb0100@yahoo.com

*** Professor, Aerospace Eng. Dept., Cairo University / gelbayoumi@yahoo.com

$\dagger$ Professor, Aerospace Eng. Dept., Cairo University / sayedhassan@hotmail.com
} 
Table 1 Altitude, velocity, and heading angle at each steering point

\begin{tabular}{c|c|c|c}
\hline \hline Steering Point & Altitude $(\mathrm{m})$ & Velocity $(\mathrm{m} / \mathrm{sec})$ & Heading $(\mathrm{deg})$ \\
\hline \hline Steering Point 1 & 300 & 70 & 100 \\
\hline Steering Point 2 & 10,000 & 350 & 165 \\
\hline Steering Point 3 & 10,000 & 350 & 224 \\
\hline Steering Point 4 & 300 & 200 & 253 \\
\hline Steering Point 5 & 13700 & 650 & 293 \\
\hline Steering Point 6 & 10,000 & 350 & 293 \\
\hline Steering Point 7 & 180 & 70 & 0 \\
\hline \hline
\end{tabular}

The target is in an air base which is $98.175 \mathrm{~nm}$ away from the take-off base and $2^{\circ}$ off to the east. The altitude of the base air field is assumed to be $150 \mathrm{~m}$. The FOXTROT a/c (a twin engined, jet fighter/bomber a/c), [2], was selected to be the example a/c, in this paper, for designing the guidance system. The usual cruise condition of this $\mathrm{a} / \mathrm{c}$ is known to be $10,000 \mathrm{~m}$ altitude at $350 \mathrm{~m} / \mathrm{sec}$. The simulation starts from just after take-off condition at $300 \mathrm{~m}$ altitude, and finishes at little lower than $180 \mathrm{~m}$ altitude. After the take-off, the vehicle has to climb to the cruise altitude, $10,000 \mathrm{~m}$, and makes a $100^{\circ}$ turn. At steering point 2 , the a/c makes $65^{\circ}$ turn. Steering for the final target approach is made at steering point 3 , and the altitude is dropped to $300 \mathrm{~m}$ which is the bomb release altitude. When releasing the bomb, the CCIP (Continuously Computed Impact Point) delivery mode is considered. As soon as the bomb is released, the vehicle rapidly increases its altitude to $13700 \mathrm{~m}$ (steering point 5) to avoid any anti-aircraft fire. At steering point 6 , the altitude is returned to the cruising condition, and the vehicle approaches the original base. The take-off and landing are not included in the mission.

\section{Guidance System Operation}

Prior to identifying the operation of the guidance system, recall the flight conditions at which the FOXTROT a/c data are available, [2], and the autopilots are designed. There are four flight conditions illustrated in Table 2. At each flight condition, there are four designed autopilots; ROC, altitude, velocity, and heading. The designed auto pilots at each flight condition are responsible for delivering the $\mathrm{a} / \mathrm{c}$ to the neighboring flight conditions where other autopilots take the responsibility, e.g., the autopilots designed at flight condition (2) is responsible for delivering the $\mathrm{a} / \mathrm{c}$ to flight conditions (1) and (3). Also the a/c can not transfer from a certain flight condition to a non-neighboring one directly, i.e., the a/c can not speed up from $70 \mathrm{~m} / \mathrm{sec}$ (flt. Cond.1) to $350 \mathrm{~m} / \mathrm{sec}$ (flt. Cond.3) directly, the guidance system will divide this process into two steps, from $70 \mathrm{~m} / \mathrm{sec}$ to $265 \mathrm{~m} / \mathrm{sec}$ (flt. Cond.2), and then from $265 \mathrm{~m} / \mathrm{sec}$ to the desired $350 \mathrm{~m} / \mathrm{sec}$.

Table 2 Altitude and velocity at each flight condition

\begin{tabular}{c|c|c}
\hline \hline Flight Condition & Altitude $(\mathrm{m})$ & Velocity $(\mathrm{m} / \mathrm{sec})$ \\
\hline \hline$(1)$ & Sea level & 70 \\
\hline$(2)$ & 10,000 & 265 \\
\hline$(3)$ & 10,000 & 350 \\
\hline$(4)$ & 13700 & 650 \\
\hline \hline
\end{tabular}


The guidance system software is divided into two programs. The first which has the interface table (Table 3) is considered the connection between the a/c operators and the guidance system; it runs on the ground for catching the data table row by row, and saving them to be used by the main program. The second is the main program which runs online to perform the main guidance system task.

Table 3 shows how the GCS software is to be filled by the operator for the a/c to accomplish the mission stated previously.

Table 3 Guidance system software interface

\begin{tabular}{|c|c|c|c|c|c|c|}
\hline Index & Priority & $\begin{array}{l}\text { Condition } \\
\text { Variable }\end{array}$ & $\begin{array}{l}\text { Condition } \\
\text { Value }\end{array}$ & $\begin{array}{c}\text { Autopilot } \\
\text { Type }\end{array}$ & $\begin{array}{c}\text { Command } \\
\text { Value }\end{array}$ & \begin{tabular}{|c} 
Disenabling \\
Condition \\
Index
\end{tabular} \\
\hline 1 & 0 & Initial & - & $\mathrm{ROC}(\mathrm{m} / \mathrm{sec})$ & 30 & 4 \\
\hline 2 & 0 & Initial & $\longrightarrow$ & Velocity $(\mathrm{m} / \mathrm{sec})$ & 265 & 5 \\
\hline 3 & 0 & Initial & & Heading (deg) & 100 & 6 \\
\hline 4 & 1 & Altitude (m) & 10,000 & Altitude (m) & 10,000 & 8 \\
\hline 5 & 2 & Velocity (m/sec) & 265 & Velocity $(\mathrm{m} / \mathrm{sec})$ & 350 & 8 \\
\hline 6 & 3 & X-Y Distance (m) & 173,162 & Heading (deg) & 165 & 7 \\
\hline 7 & 4 & X-Y Distance (m) & 190,520 & Heading (deg) & 224 & 11 \\
\hline 8 & 5 & Just After Previous & & $\mathrm{ROC}(\mathrm{m} / \mathrm{sec})$ & -90 & 9 \\
\hline 9 & 6 & Altitude (m) & 300 & Altitude (m) & 300 & 12 \\
\hline 10 & 6 & Altitude (m) & 300 & Velocity $(\mathrm{m} / \mathrm{sec})$ & 200 & 13 \\
\hline 11 & 6 & Altitude (m) & 300 & Heading (deg) & 253 & 18 \\
\hline 12 & 7 & External Signal & CCIP signal & $\mathrm{ROC}(\mathrm{m} / \mathrm{sec})$ & 50 & 16 \\
\hline 13 & 7 & External Signal & CCIP signal & Velocity $(\mathrm{m} / \mathrm{sec})$ & 265 & 14 \\
\hline 14 & 8 & Velocity (m/sec) & 265 & Velocity (m/sec) & 350 & 15 \\
\hline 15 & 9 & Velocity $(\mathrm{m} / \mathrm{sec})$ & 350 & Velocity $(\mathrm{m} / \mathrm{sec})$ & 650 & 19 \\
\hline 16 & 10 & Altitude (m) & 10,000 & $\mathrm{ROC}(\mathrm{m} / \mathrm{sec})$ & 50 & 17 \\
\hline 17 & 11 & Altitude (m) & 13,700 & Altitude (m) & 13,700 & 19 \\
\hline 18 & 12 & X-Y Distance (m) & 162,420 & Heading (deg) & 293 & 22 \\
\hline 19 & 13 & Just After Previous & $\longrightarrow$ & $\mathrm{ROC}(\mathrm{m} / \mathrm{sec})$ & -50 & 20 \\
\hline 20 & 14 & Altitude (m) & 10,000 & Altitude (m) & 10,000 & \\
\hline 21 & 15 & Just After Previous & $\longrightarrow$ & Velocity $(\mathrm{m} / \mathrm{sec})$ & 350 & . \\
\hline 22 & 16 & X-Y Distance (m) & 122,232 & Heading (deg) & 0 & . \\
\hline · & & $\cdot$ & . & . & . & - \\
\hline · & & . & . & . & . & . \\
\hline & & & . & & . & \\
\hline
\end{tabular}

Now the interface table will be identified:

- Each row represents a task that the a/c has to perform.

- The index field is a counter that is filled automatically by the software.

- The priority field is filled in a chronological order to tell the system which task has to be accomplished first.

- The condition variable is a pull down menu containing seven choices; initial, altitude, velocity, heading, $x-y$ distance, external signal, and just after previous. This column tells the guidance system when the task of this row has to be started; initially just after running the program, when the altitude reaches certain value, the velocity, the 
heading, the $\mathrm{x}-\mathrm{y}$ distance, when an external signal arrival, or just after the previous task settles.

- The condition value field represents the value when the condition variable specified above reaches, the guidance system starts performing the task.

- The auto pilot (A/P) type is a pull down menu containing the four types of the existing auto pilots; it represents the task of this row that should be done.

- The command field asks about the set point (command input) of the specified autopilot.

- The disabling-condition-index field is filled after filling all the rows; it represents the index number of the condition at which it is intended to disable this task.

- Each row has an add button that should be clicked after entering the row data, and the system software checks for the a/c ability to perform this task. If it is not able, the software suggests appropriate alternative series of tasks.

The take off autopilot delivers the a/c to $300 \mathrm{~m}$ altitude, $70 \mathrm{~m} / \mathrm{sec}$ velocity. At then the a/c has to perform three tasks; climbing with $30 \mathrm{~m} / \mathrm{sec}$ ROC to $10,000 \mathrm{~m}$ altitude, increasing the velocity to $350 \mathrm{~m} / \mathrm{sec}$, and turning to $100^{\circ}$ heading. The following lines illustrate some of the operators' task row by row, and the way by which the guidance system software $(\mathrm{s} / \mathrm{w})$ responds:

First row: the priority fields were filled by zeros and the conditions were chosen initially in the three tasks to be performed firstly. The autopilot type was selected to be ROC, the command value set to $30 \mathrm{~m} / \mathrm{sec}$, and the add button was then clicked. The s/w then asks about the altitude to be reached, it is set to $10,000 \mathrm{~m}$, so it suggested the next row data to be filled with priority: one, condition: altitude, value: $10,000 \mathrm{~m}, \mathrm{~A} / \mathrm{P}$ type: altitude, and the command value: 10,000 , i.e., the $\mathrm{s} / \mathrm{w}$ suggests altitude hold when the $\mathrm{a} / \mathrm{c}$ reaches the desired altitude.

Second row: the A/P type was chosen to be velocity, the command value set to $350 \mathrm{~m} / \mathrm{sec}$, and the add button was then clicked. The s/w checks the validity of this command, the selected condition at which this task should be done is initially ( $300 \mathrm{~m}$ altitude, $70 \mathrm{~m} / \mathrm{sec}$ ), so the a/c cannot reach $350 \mathrm{~m} / \mathrm{sec}$ (flt. Cond.3) from $70 \mathrm{~m} / \mathrm{sec}$ (flt. Cond.1) as stated before. Therefore, the s/w refused, suggested the command of this row to be $265 \mathrm{~m} / \mathrm{sec}$ (flt. Cond.2) and suggested the next row to have apriority: two, condition: velocity, value: $265 \mathrm{~m} / \mathrm{sec}, \mathrm{A} / \mathrm{P}$ type: velocity, and the command value: 350 , i.e., the s/w suggests reaching from 70 to 350 $\mathrm{m} / \mathrm{sec}$ in two steps.

Sixth row: to understand the condition which was selected "x-y distance". After studying the mission profile in the $x-y$ plane, it is found that the turning at steering point 2 is done when the $\mathrm{a} / \mathrm{c}$ is at an $\mathrm{x}-\mathrm{y}$ distance from the base equals $93.5 \mathrm{~nm}(173,162 \mathrm{~m})$, so it is the condition for turning to $165^{\circ}$.

Eighth row: The condition here is selected "just after previous". Every designed auto pilot gives a signal after setting its mission. In this row it is intended to descend to the target air base field after the heading angle reaches the desired value, i.e. the heading auto pilot settles, so it's the condition for descending.

Twelfth row: In this row it is intended that the a/c climbs increasing its velocity after the bomb has been released, therefore the condition for the $\mathrm{a} / \mathrm{c}$ to start doing so is the external signal coming from the CCIP mode telling us that the bomb release has finished. 
The $\mathrm{a} / \mathrm{c}$ operators fill the data table to the end of mission, and then they enter the disenabling condition for each row task, and click finish. The system s/w runs a simulation for the whole mission to be checked by the operators, if they are not satisfied with the simulated mission, they can edit the mission rows and check again. Going to the design step of the main program, which is responsible for the $\mathrm{a} / \mathrm{c}$ to accomplish the entered mission.

\section{Guidance System Design}

The guidance system input is the mission data (Table 3), its output is the switching on/off signals to the specified autopilots at the appropriate times. Figure 3 illustrates the flow chart of the guidance system s/w, Fig. 4, 5 represent the flow charts of the functions used in the main guidance system program, and Fig. 6. shows the disenable subroutine used in the disengage function.

\section{References}

[1] Yu, Si-bok, "Life-extending control for a highly maneuverable flight vehicle", Ph.D. Thesis, Old Dominion University, 2003.

[2] Donald McLean, "Automatic Flight Control Systems", Prentice Hall International Ltd, UK, 1990.

[3] J. C. Neidhoefer and K. Krishnakumar, "Intelligent Control for Near-Autonomous Aircraft Missions", IEEE, Jan 2001.

[4] Gary B. Lamont, "UAV Swarm Mission Planning Development Using Evolutionary Algorithms", Air Force Institute of Technology, OH, USA.

[5] Mario Andres Cordoba, "Autonomous Intelligent Fuzzy Logic Guidance, and Flight Control System for the EFIGENIA EJ-1B Mozart UAV", 17th IFAC Symposium on Automatic Control in Aerospace, Toulouse.

[6] Djaber Boukraa, Yasmina Bestaoui, and Naoufel Azouz, "3D Trajectory Tracking for a Fixed Wing UAV Using Dynamic Inversion", 17th IFAC Symposium on Automatic Control in Aerospace, Toulouse.

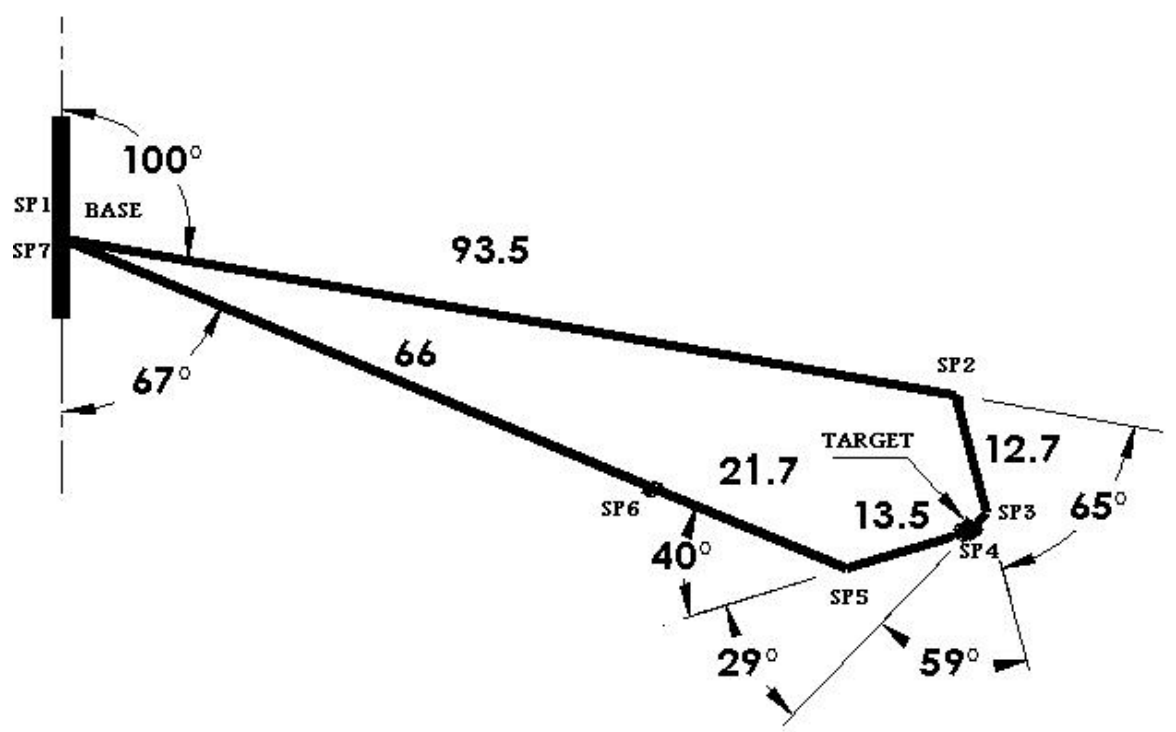

Fig. 1 Plane view of the mission. 


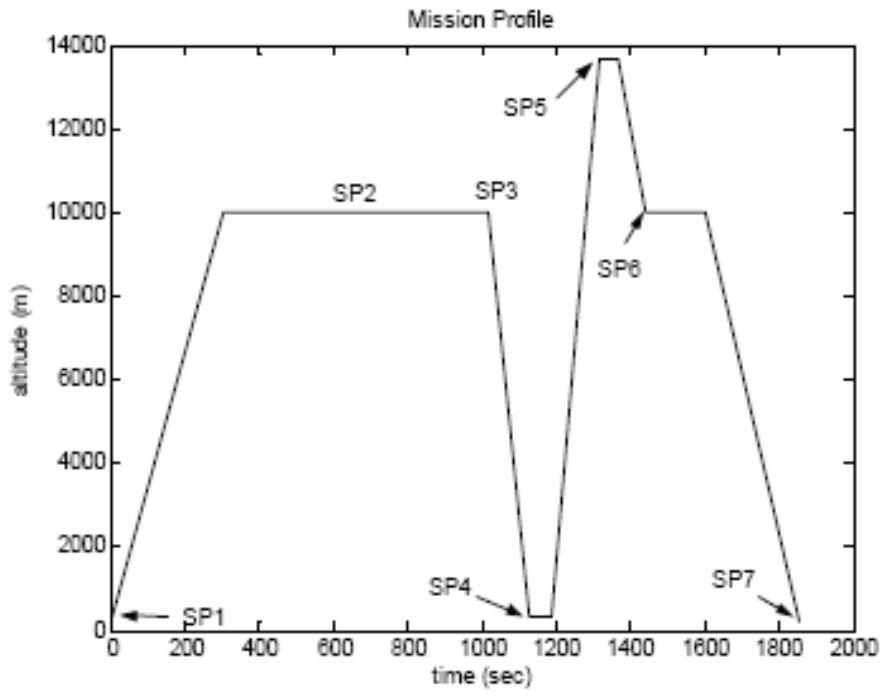

Fig. 2 Altitude of the mission profile.

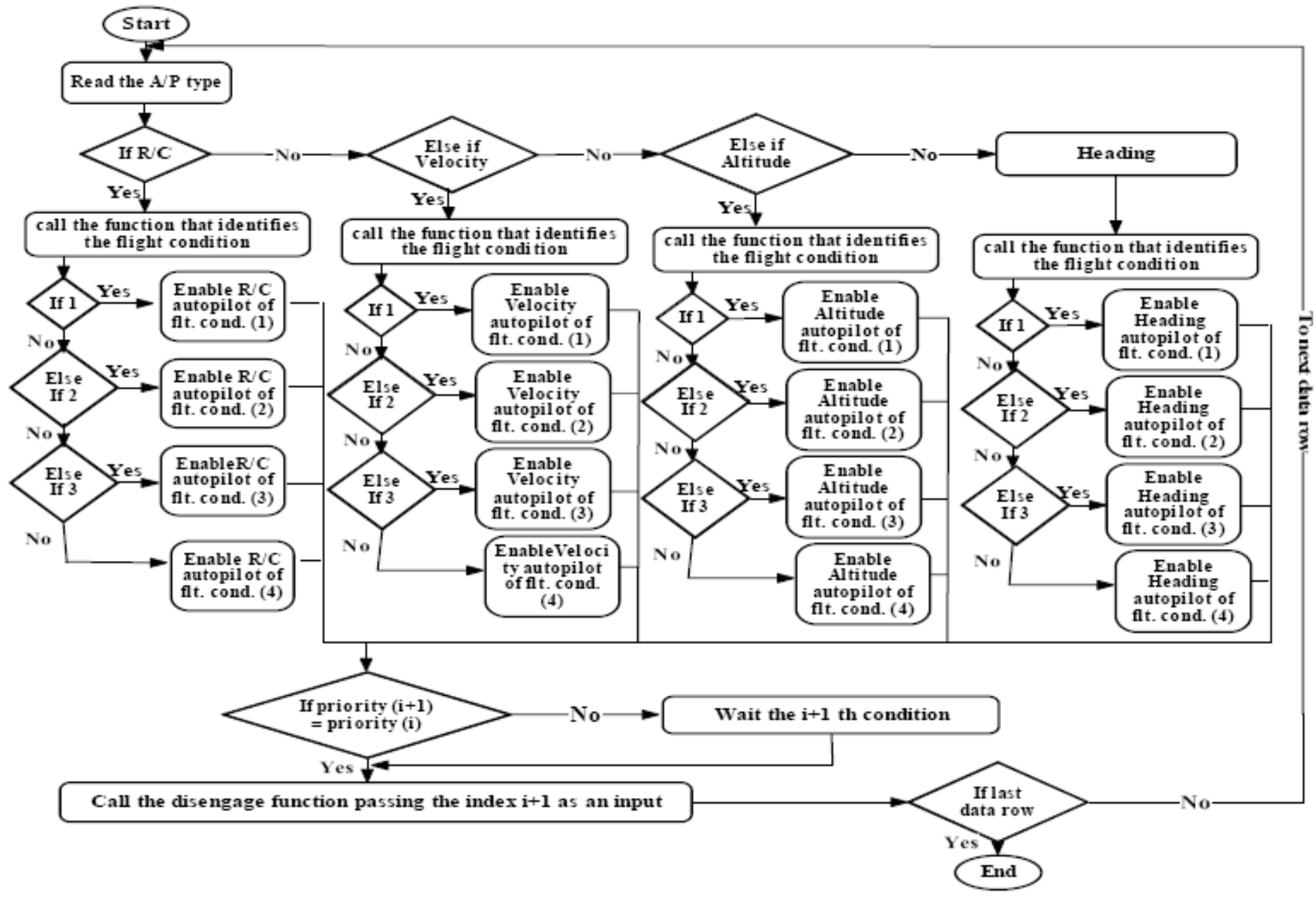

Fig. 3 Guidance system software 


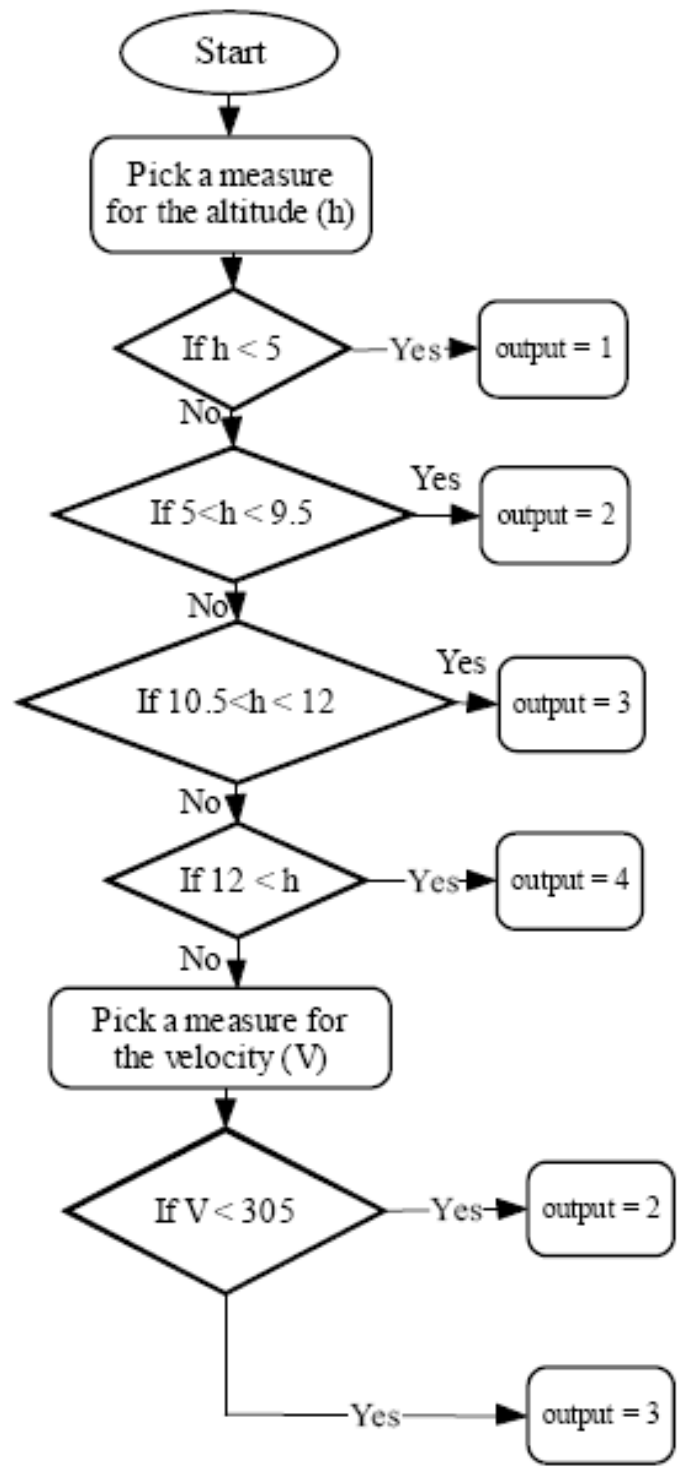

Fig. 4 Flow chart of the function that identifies the flight condition, used in the main program of the guidance system.

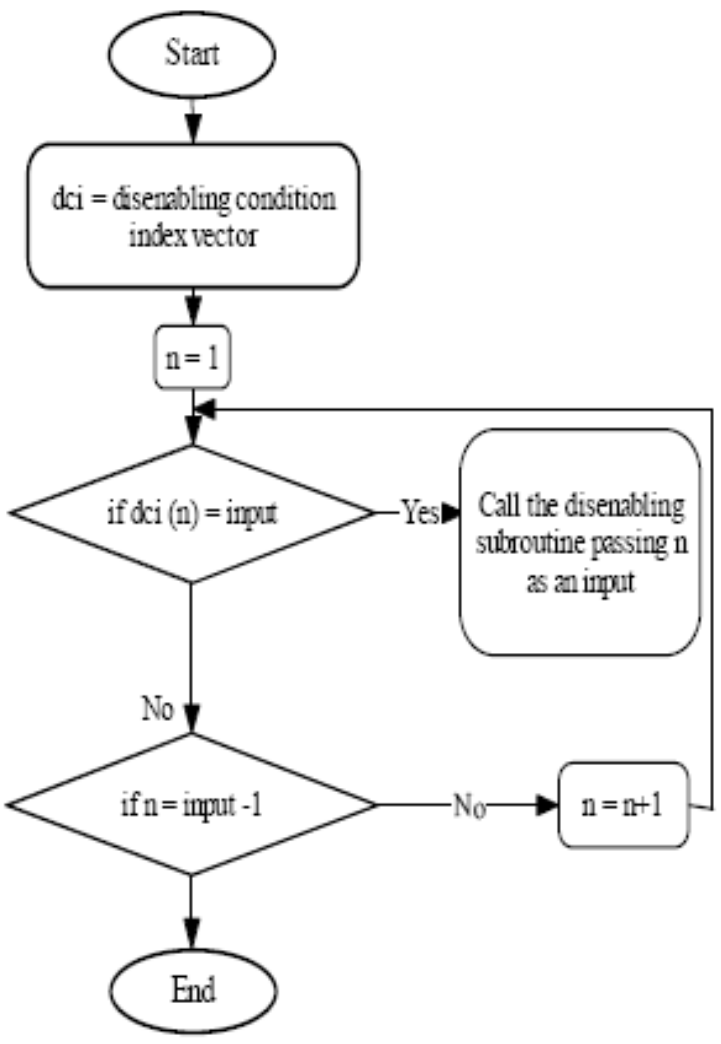

Fig. 5 Flow chart of the disengage function, used in the main program of the guidance system 


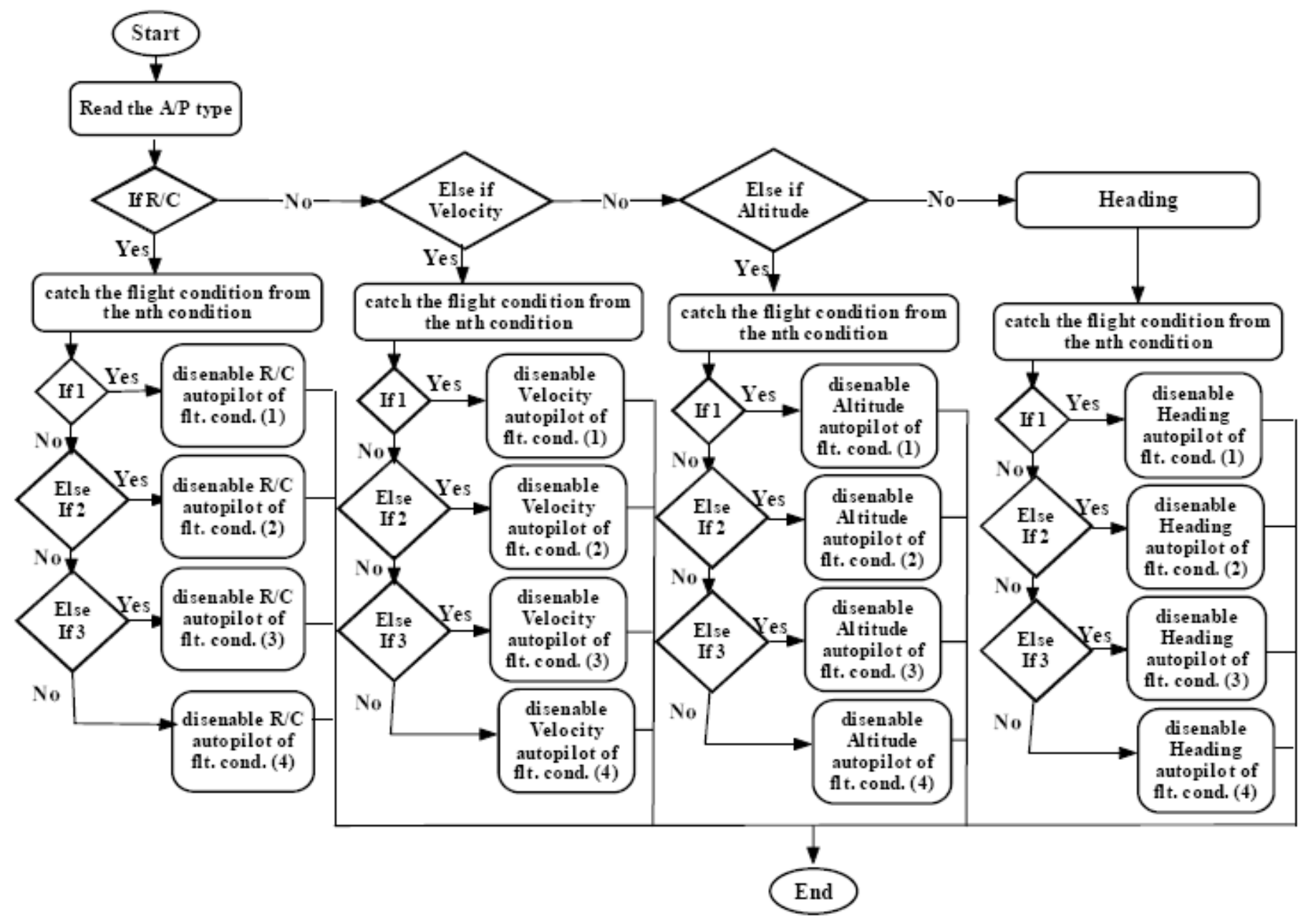

Fig. 6 Disenable subroutine, used in the disengage function 